\title{
The effect of physically or non-physically forced sexual assault on trajectories of sport participation from adolescence through young adulthood
}

\author{
Chung Gun Lee', Junhye Kwon ${ }^{1}$, Hojun Sung ${ }^{1}$, Inae Oh', Ohsup Kim', Jeehyun Kang ${ }^{1}$ and Ji-Won Park ${ }^{2^{*}}$ (D)
}

\begin{abstract}
Background: Sexual assault is one of potential factors that may greatly affect an individual's sport participation. The purpose of this study is to investigate the effect of experiencing physically or non-physically forced sexual activity on trajectories of sport participation from adolescence to young adulthood.

Methods: This study used the National Longitudinal Study of Adolescent Health (Add Health) data. Group-based trajectory modeling was utilized to examine the effect of experiencing sexual assault on trajectories of sport participation from adolescence to young adulthood.

Results: A three-group trajectory model (high-stable group, high-decreasing group, and low-stable group) best fit sport participation among male participants and a two-group trajectory model (high-decreasing group and lowstable group) best fit sport participation among female participants. Both physically and non-physically forced sexual activity did not have significant effect on trajectories of sport participation among male participants. On the other hand, non-physically forced sexual assault significantly affected sport participation trajectory among female participants.
\end{abstract}

Conclusions: Special care is required in developing sport promotion program for women victims of non-physically forced sexual activity. The results of this study also suggest that group-based trajectory modeling is a useful technique to examine distinct trajectories of sport participation from adolescence through young adulthood.

Keywords: Sexual assault, Sport participation, Group-based trajectory modeling, Adolescent, Young adult

\section{Background}

Engaging in regular physical activity has been shown to reduce the risk of developing chronic diseases, such as coronary heart disease, stroke, hypertension, various types of cancer, Type 2 diabetes mellitus, and osteoporosis [1]. Performing regular physical activity also has been shown to have beneficial effects on psychological

\footnotetext{
* Correspondence: julia_park@naver.com

${ }^{2}$ Department of Taekwondo, College of Sports Science, Woosuk University, 443 Samnye-ro, Samnye-eup, Wanju-gun, Jeollabuk-do 55338, South Korea Full list of author information is available at the end of the article
}

well-being through enhancing self-esteem and reducing psychological distress [1]. Despite the known health benefits of regular physical activity, the prevalence of physical activity among adults (aged 18 or older) has been still unsatisfactory [2]. One of the most efficient ways to promote regular physical activity is through sport participation because participating in sports makes physical activity more enjoyable through competition, social interaction, goal achievement, and personal challenge [3]. Moreover, most sporting activities easily meet recent physical activity recommendations suggested by

C The Author(s). 2020 Open Access This article is licensed under a Creative Commons Attribution 4.0 International License, which permits use, sharing, adaptation, distribution and reproduction in any medium or format, as long as you give appropriate credit to the original author(s) and the source, provide a link to the Creative Commons licence, and indicate if changes were made. The images or other third party material in this article are included in the article's Creative Commons licence, unless indicated otherwise in a credit line to the material. If material is not included in the article's Creative Commons licence and your intended use is not permitted by statutory regulation or exceeds the permitted use, you will need to obtain permission directly from the copyright holder. To view a copy of this licence, visit http://creativecommons.org/licenses/by/4.0/. The Creative Commons Public Domain Dedication waiver (http://creativecommons.org/publicdomain/zero/1.0/) applies to the data made available in this article, unless otherwise stated in a credit line to the data. 
American College of Sports Medicine (ACSM) [4]. It is, therefore, important to investigate the factors that may influence sport participation because participation in sporting activities almost always involves physical activity.

Life change events, such as obtaining a new job, a change in marital status, parental incarceration, experiencing sexual assault, pregnancy, and the death of a family member, can be defined as "those occurrences, including social, psychological and environmental, which require an adjustment or effect a change in an individual's pattern of living." [5]. Such events are potential factors that may greatly affect an individual's physical activity-related behaviors (e.g., sport participation, exercise, and outdoor recreation). Although life change events may affect a person's commitment to be physically active by creating emotional distress and disturbing an individual's daily routine, the effect of life change events on physical activity-related behaviors is poorly studied [6]. Certain life change events were shown to have strong effects on physical activity-related behavior but more research is needed to investigate the longerterm effects of different life change events on physical activity-related behaviors [6]. Among various life change events, this study focused on experiencing sexual assault.

A recent study showed that $23.4 \%$ of men and $43.9 \%$ of women have experienced various forms of sexual violence, such as being made to penetrate, non-physically pressured unwanted penetration, and kissing or fondling, during their lifetimes in the United States [7]. Breiding et al. also reported that $1.7 \%$ of men and $19.3 \%$ of women have experienced completed rape at some point in their lives [7]. Sexual assault is a serious public health problem especially for women because experiencing sexual assault places women at risk of various deleterious physical and psychological health outcomes, including depressive symptoms, suicidal ideation, posttraumatic stress disorder (PTSD) symptoms, anxiety, greater health care utilization, self-reported health complaints, and chronic health conditions [8-13]. These negative effects of sexual assault on psychological and physical health are known to persist for long periods of time $[8,14,15]$.

Moreover, experiencing sexual assault is also associated with health-related behaviors, such as sexual intercourse as an affect regulation strategy [16] and problematic drinking [17-19]. The predominant hypothesis about this association is that sexual assault survivors engage in risky behaviors that are intended to cope with the psychological distress that results from their experience of sexual abuse, but which impair their physical health. Ullman et al. found that posttraumatic stress disorder (PTSD) symptoms mediated the effect of child sexual abuse on problematic drinking among adult women [20]. Goldstein et al. (2010) also found that among college students the motives for drinking (i.e., coping with depression) mediated the relation between childhood abuse and consequences of drinking. Although there are several studies that investigated the effect of experiencing sexual assault on health-related behaviors, few studies have considered psychological distress as a potential mediator of this relationship and, to our knowledge, none of the studies examined physical activity-related behaviors among victims of sexual assault. Since sexual assault survivors are likely to be harmed by societal stereotypes that aggravate victim blaming [21], it is possible that impaired mental health caused by societal stereotypes may limit survivors' physical activity or sport participation.

Although some evidence supports the notion that experiencing sexual assault can affect physical activityrelated behaviors, the extent and nature of these relationships across the lifespan are unclear. The National Longitudinal Study of Adolescent Health (Add Health), which prospectively followed up a nationally representative sample of middle and high school students in the United States [22], provides an opportunity to explore the effects of life change events on trajectories of sport participation from adolescence through young adulthood. The purpose of this study is to investigate the effect of experiencing physically or non-physically forced sexual activity on trajectories of sport participation from adolescence to young adulthood. We investigated separately by gender because women may be deleteriously affected by sexual assault in a different way or to a different degree than men [23-25] and it has been shown that men engage in higher levels of physical activity than women [2]. We also considered psychological depression as a mediator of the relationship between experiencing sexual assault and sport participation because previous studies supported the importance of psychological distress as a potential mediator of this relationship [16, 20, 26].

\section{Methods \\ Data}

This study used the National Longitudinal Study of Adolescent Health (Add Health) data. Add Health is a fourwave longitudinal study that prospectively followed up a nationally representative sample of 7 th through 12th grade students (middle and high school students) in the United States. All public and private high schools in the United States that included more than 30 students were included in the initial sampling frame and these high schools were stratified by ethnic mix, size, urbanicity, region, and school type. Eighty high schools were then selected using systematic random sampling and approximately $70 \%$ of these schools were recruited. All public and private middle schools in the United States that sent 
graduates to recruited high schools were also recruited. A total of 134 schools were included in the final sample. In each school, students were randomly selected from official school rosters after stratification for age and grade. Wave 1 in-home survey was conducted from April to December in $1995(n=20,745)$. The first follow-up survey (wave 2) was conducted approximately 1 year later $(n=14,738)$. Wave $3(n=15,197)$ and $4(n=15,701)$ in-home survey were conducted 6 and 12 years after wave 1 , respectively. Further information about Add Health is reported elsewhere [22]. The present study used wave 1 through 4 public-use datasets $(n=6504)$.

\section{Measures}

Sport participation at each wave was assessed via a question, "During the past week, how many times did you play an active sport, such as baseball, softball, basketball, soccer, swimming, or football?" According to the American College of Sports Medicine (ACSM), people need to engage in moderate to vigorous physical activity at least 30 min per day on 5 days per week in order to maintain their health [27]. Therefore, a participant who participated in sports 5 or more times during the past week defined as an active participator. Because sport participation at wave 3 and 4 was assessed by asking two questions, "In the past seven days, how many times did you participate in individual sports such as running, wrestling, swimming, cross-country skiing, cycle racing, or martial arts?" and "In the past seven days, how many times did you participate in strenuous team sports such as football, soccer, basketball, lacrosse, rugby, field hockey, or ice hockey?", the number of times participated in team and individual sports were combined to create a total number of participation in sports.

Physically forced sexual activity in each wave was assessed in wave 4 via two questions, "Have you ever been physically forced to have any type of sexual activity against your will?" and "How old were you the first or only time this happened?" If a participant was physically forced to have sexual activity before each wave of the survey, he or she was defined as a participant who experienced physically forced sexual assault. Non-physically forced sexual activity in each wave was assessed in wave 4 by asking two questions, "Have you ever been forced, in a non-physical way, to have any type of sexual activity against your will? For example, through verbal pressure, threats of harm, or by being given alcohol or drugs?" and "How old were you the first or only time this happened?" If a participant was non-physically forced to have sexual activity before each wave of the survey, he or she was defined as a participant who experienced non-physically forced sexual abuse.
A short version of the Center for Epidemiologic Studies-Depression Scale (CES-D) was utilized to evaluate participants' psychological depression at each wave $[28,29]$. After reverse coding several items, depression scores for each item were summed to indicate psychological depression at each wave.

\section{Statistical analysis}

The present study utilized group-based trajectory modeling to examine the effect of experiencing sexual assault on trajectories of sport participation from adolescence to young adulthood. Since sport participation is a binary variable, binary logit models were fitted to estimate trajectories of sport participation using SAS Traj procedure [30]. The wave was used as a time scale (wave $1=1996$, wave $2=1997$, wave $3=2001$, and wave $4=2008$ ) and was centered at wave 1 (wave $1=0$, wave $2=1$, wave $3=6$, and wave $4=12$ ). The number of trajectory groups and the shape of each trajectory group were selected based on statistical [31] and non-statistical criteria [32]. These criteria for identifying the best fitting model included the Bayesian Information Criterion (BIC), average posterior probabilities of group assignment, and percentages of observations assigned to each group. Subjective judgment is also used in model selection because it is important to identify useful and parsimonious model [32]. Once the best fitting model was identified, timevarying covariates were added into the model. The purpose of this modeling extension is to examine the effect of physically or non-physically forced sexual activity on sport participation trajectories [33]. The function called "tcov" is used to direct SAS Traj procedure to calculate the trajectory for each group under an author-specified set of values of timevarying covariate. The command "plottcov 111111 " was also used to direct SAS Traj procedure to estimate the predicted trajectories under the assumption that experiencing sexual assault equals 1 in all waves. This function allows us to see sport participation trajectories for those who experienced sexual assault before wave 1. Psychological depression was also included in the model as time-varying covariate because it is a potential mediator of the relationship between experiencing sexual assault and sport participation. Characteristics of participants were presented as frequency and percent for categorical variables and mean and standard deviation for continuous variables. Comparisons between trajectory groups were performed using chi-square test for categorical variables and analysis of variance (ANOVA) for continuous variables. All analyses were performed using SAS version 9.4 (SAS Institute Inc., Cary, NC). 


\section{Results}

\section{Descriptive statistics}

Table 1 shows characteristics of participants by sport participation trajectory group. The mean age of male participants was 15.61 years at wave 1 . Male participants were divided into three sport participation trajectory groups (i.e., low-stable group, high-decreasing group, and high-stable group). The low-stable group consistently had low probability of sport participation from adolescence to young adulthood. The remaining two groups both started with high probability of participating in sports, one maintaining that pattern until they become young adult (high-stable group), the other being less likely to participate in sports with time (high-decreasing group). Low-stable group had the highest mean depression score and high-stable group had the lowest mean depression score. At each wave, the prevalence of experiencing physically and non-physically forced sexual assault was similar across groups. Table 1 also represents characteristics of female participants by sport participation trajectory group. Unlike male participants, there were only two sport participation trajectory groups in female participants (i.e., low-stable group and high-decreasing group). The mean age of female participants at wave 1 (15.46 years) was similar to that of male participants. Low-stable group had higher mean depression score than high-decreasing group at each wave. The prevalence of experiencing physically and nonphysically forced sexual activity was similar between two trajectory groups.

\section{Group-based trajectory modeling}

A three-group trajectory model best fit sport participation among male participants (see Fig. 1 and Table 2). About half (46.39\%) of male participants were assigned to low-stable group. The remaining male participants started with high probability of participating in sports, $16.15 \%$ of them maintaining that pattern until they become young adult (high-stable group), $37.46 \%$ of them being less likely to participate in sports with time (high-decreasing group). A twogroup trajectory model best fit sport participation among female participants (see Fig. 1 and Table 2). Most female participants $(68.30 \%)$ were assigned to low-stable group. The remaining female participants $(31.70 \%)$ had high probability of sport participation during adolescence and then it decreased until they become young adult.

Tables 3 and 4 represent the effect of experiencing physically and non-physically forced sexual activity on sport participation trajectories, respectively. Both physically and non-physically forced sexual activity did not have significant effect on sport participation among male participants. On the other hand, nonphysically forced sexual assault significantly affected sport participation among female participants. Female participants who experienced non-physically forced sexual activity were significantly less likely to participate in sports throughout the trajectory in highdecreasing group (see Fig. 2). However, the significant effect of non-physically forced sexual activity on women's sport participation became insignificant after controlling for psychological depression.

\section{Discussion}

To our knowledge, this is the first study that examined the effect of physically or non-physically forced sexual activity on trajectories of sport participation from adolescence through young adulthood using group-based trajectory modeling. In Add Health data, stratified sampling was utilized with the purpose of gathering data that is inclusive of diverse racial backgrounds and genders. Male participants were divided into three trajectory groups. The largest group (46.39\%) consistently had low probability of sport participation from adolescence to young adulthood. The remaining two groups both started with high probability of participating in sports, one (16.15\%) maintaining that pattern until they become young adult, the other $(37.46 \%)$ being less likely to participate in sports with time. On the other hand, females were divided into only two trajectory groups. The majority group $(68.30 \%)$ steadily had low probability of participating in sports throughout the study period. The other group $(31.70 \%)$ had high probability of sport participation at the beginning and then it decreased over time. An interesting finding is that there is no "low-increasing group" in both gender groups. This result is in line with the previous studies suggesting that overall prevalence of physical activity or sport participation decreases during the transition from adolescence to adulthood [34] and, therefore, participation in sports or any type of physical activity during adolescence can never be emphasized enough [35]. School physical education and other programs affecting physical activity-related behaviors among adolescents should strive to develop and implement efficient physical activity programs. Moreover, future studies should be conducted to find out factors that influence sustainable physical activity behavior that continues throughout the lifespan especially for females because there was no "high-stable group" among female participants in this study.

The main finding of this study is that women who experienced non-physically forced sexual activity were significantly less likely to participate in sports throughout the trajectory in "high-decreasing group". 
Table 1 Characteristics of participants by sport participation trajectory group $(N=3147)$

\begin{tabular}{|c|c|c|c|c|c|}
\hline \multirow[t]{2}{*}{ Characteristics } & \multirow{2}{*}{$\begin{array}{l}\text { Total } \\
\text { sample }\end{array}$} & \multicolumn{3}{|c|}{ Sport participation trajectory groups } & \multirow[t]{2}{*}{$p$-value } \\
\hline & & Low-stable & High-decreasing & High-stable & \\
\hline \multicolumn{6}{|l|}{ Male participants } \\
\hline Mean age at wave $1(S D)$ & $15.61(1.79)$ & $15.92(1.79)$ & $15.27(1.71)$ & $15.12(1.74)$ & $<.0001$ \\
\hline \multicolumn{6}{|l|}{ Mean depression (SD) } \\
\hline Wave 1 & $4.33(3.29)$ & $4.68(3.41)$ & $4.00(3.12)$ & $3.64(3.03)$ & $<.0001$ \\
\hline Wave 2 & $4.20(3.26)$ & $4.48(3.43)$ & $3.99(3.12)$ & $3.72(2.87)$ & 0.0001 \\
\hline Wave 3 & $3.50(3.13)$ & $3.52(3.09)$ & $3.65(3.30)$ & $2.99(2.74)$ & 0.0097 \\
\hline Wave 4 & $4.29(3.25)$ & $4.40(3.32)$ & $4.27(3.17)$ & $3.82(3.10)$ & 0.0289 \\
\hline \multicolumn{6}{|c|}{ Ever forced to have sex in a non-physical way (\%) } \\
\hline Wave 1 & $42(1.79)$ & $21(1.64)$ & $18(2.26)$ & $3(1.09)$ & 0.3828 \\
\hline Wave 2 & $46(1.96)$ & $22(1.72)$ & $20(2.51)$ & $4(1.46)$ & 0.3667 \\
\hline Wave 3 & $63(2.68)$ & $28(2.19)$ & $28(3.52)$ & $7(2.55)$ & 0.1886 \\
\hline Wave 4 & $82(3.49)$ & $40(3.13)$ & $33(4.15)$ & $9(3.28)$ & 0.4609 \\
\hline \multicolumn{6}{|c|}{ Ever forced to have sex in a physical way (\%) } \\
\hline Wave 1 & $34(1.45)$ & $16(1.25)$ & $13(1.64)$ & $5(1.82)$ & 0.6597 \\
\hline Wave 2 & $34(1.45)$ & $16(1.25)$ & $13(1.64)$ & $5(1.82)$ & 0.6597 \\
\hline Wave 3 & $38(1.62)$ & $19(1.48)$ & $14(1.76)$ & $5(1.82)$ & 0.8488 \\
\hline Wave 4 & $43(1.83)$ & $22(1.72)$ & $15(1.89)$ & $6(2.19)$ & 0.8583 \\
\hline \multicolumn{6}{|c|}{ Sport participation $\geq 5$ times per week (\%) } \\
\hline Wave 1 & $1067(33.94)$ & $0(0.00)$ & $849(75.60)$ & $218(71.01)$ & $<.0001$ \\
\hline Wave 2 & $781(33.75)$ & $0(0.00)$ & $607(65.48)$ & $174(67.18)$ & $<.0001$ \\
\hline Wave 3 & $273(12.17)$ & $59(4.91)$ & $0(0.00)$ & $214(76.70)$ & $<.0001$ \\
\hline Wave 4 & $218(9.27)$ & $61(4.76)$ & $0(0.00)$ & $157(57.30)$ & $<.0001$ \\
\hline Total (\%) & 3147 & $1716(46.39)$ & $1123(37.46)$ & $308(16.15)$ & \\
\hline \multicolumn{6}{|l|}{ Female participants } \\
\hline Mean age at wave $1(S D)$ & $15.46(1.78)$ & $15.72(1.76)$ & $14.69(1.62)$ & & $<.0001$ \\
\hline \multicolumn{6}{|l|}{ Mean depression (SD) } \\
\hline Wave 1 & $5.43(3.89)$ & $5.66(3.96)$ & $4.74(3.59)$ & & $<.0001$ \\
\hline Wave 2 & $5.57(3.94)$ & $5.71(3.94)$ & $5.22(3.92)$ & & 0.0051 \\
\hline Wave 3 & $4.33(3.80)$ & $4.40(3.80)$ & $4.16(3.78)$ & & 0.1514 \\
\hline Wave 4 & $5.09(3.77)$ & $5.20(3.80)$ & $4.78(3.65)$ & & 0.0113 \\
\hline \multicolumn{6}{|c|}{ Ever forced to have sex in a non-physical way (\%) } \\
\hline Wave 1 & $224(8.15)$ & $181(8.80)$ & $43(6.20)$ & & 0.0306 \\
\hline Wave 2 & $260(9.46)$ & $205(9.97)$ & $55(7.94)$ & & 0.1135 \\
\hline Wave 3 & $416(15.13)$ & $318(15.47)$ & $98(14.14)$ & & 0.3998 \\
\hline Wave 4 & $547(19.90)$ & $415(20.18)$ & $132(19.05)$ & & 0.5167 \\
\hline \multicolumn{6}{|c|}{ Ever forced to have sex in a physical way (\%) } \\
\hline Wave 1 & $166(6.02)$ & $131(6.35)$ & $35(5.05)$ & & 0.2135 \\
\hline Wave 2 & $183(6.64)$ & $143(6.93)$ & $40(5.77)$ & & 0.2888 \\
\hline Wave 3 & $300(10.89)$ & $224(10.86)$ & $76(10.97)$ & & 0.9366 \\
\hline Wave 4 & $386(14.01)$ & $291(14.11)$ & $95(13.71)$ & & 0.7944 \\
\hline \multicolumn{6}{|c|}{ Sport participation $\geq 5$ per week (\%) } \\
\hline Wave 1 & 515 (15.35) & $0(0.00)$ & $515(62.12)$ & & $<.0001$ \\
\hline Wave 2 & $422(16.75)$ & $0(0.00)$ & $422(58.29)$ & & $<.0001$ \\
\hline
\end{tabular}


Table 1 Characteristics of participants by sport participation trajectory group ( $N=3147)$ (Continued)

\begin{tabular}{|c|c|c|c|c|c|}
\hline \multirow[t]{2}{*}{ Characteristics } & \multirow{2}{*}{$\begin{array}{l}\text { Total } \\
\text { sample }\end{array}$} & \multicolumn{3}{|c|}{ Sport participation trajectory groups } & \multirow[t]{2}{*}{$p$-value } \\
\hline & & Low-stable & High-decreasing & High-stable & \\
\hline Wave 3 & $134(5.12)$ & $0(0.00)$ & $134(19.45)$ & & $<.0001$ \\
\hline Wave 4 & $115(4.17)$ & $62(3.00)$ & $53(7.65)$ & & $<.0001$ \\
\hline Total (\%) & 3356 & $2527(68.30)$ & $829(31.70)$ & & \\
\hline
\end{tabular}

Missing data were excluded in calculating the percentage

(a) Male participants

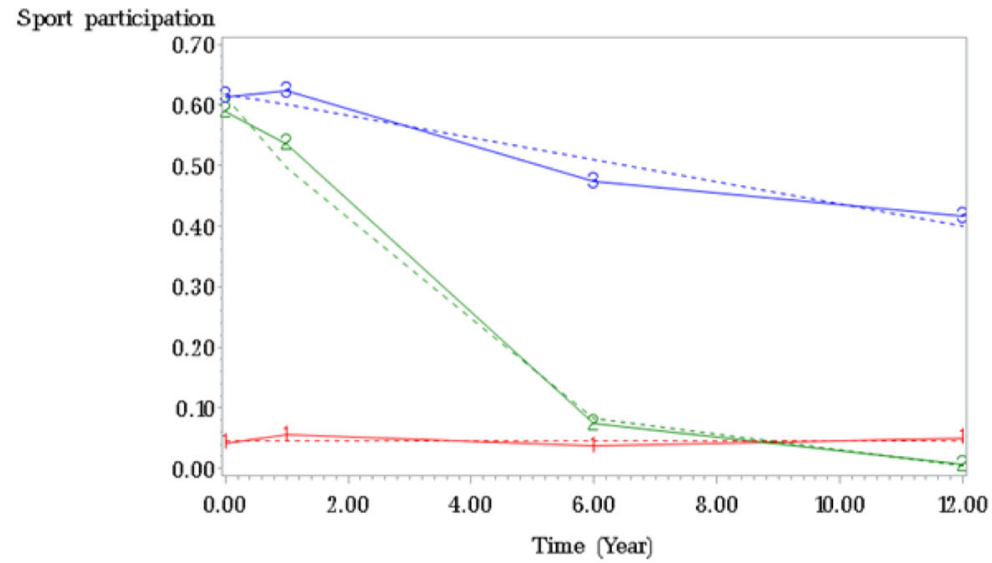

(b) Female participants

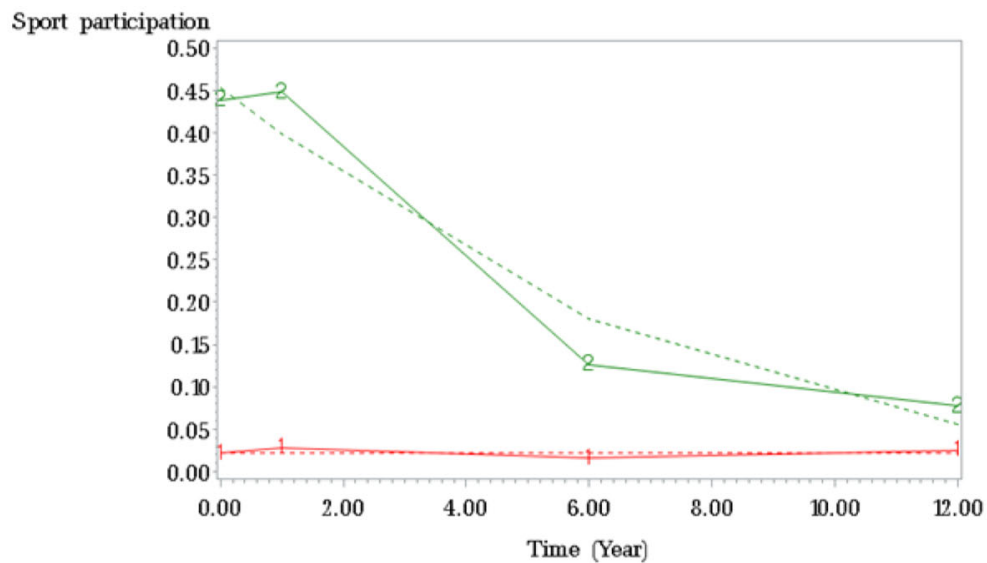

\section{$+1+$ Low-stable group}

222 High-decreasing group

\section{$3-3$ High-stable group}

Note. Solid line represents average data and dashed line represents mean trajectories.

Fig. 1 Trajectories of sport participation from adolescence through young adulthood. a Male participants. b Female participants. $\mathbf{z}-\mathbf{z}-\mathbf{z}$ Lowstable group. 22,2 High-decreasing group. $z-3-3$ High-stable group. Note. Solid line represents average data and dashed line represents mean trajectories 
Table 2 Bayesian information criterion for selection of models

\begin{tabular}{lllll}
\hline Gender & Model & Number of groups & Order & BIC \\
\hline Men & 1 & 4 & $2,2,2,2$ & -4912.57 \\
& 2 & 3 & $0,1,1$ & -4894.60 \\
& 3 & 3 & $2,2,2$ & -4898.28 \\
& 4 & 2 & 2,2 & -4908.40 \\
\multirow{4}{*}{ Women } & 5 & 1 & 2 & -5074.67 \\
& 1 & 3 & $2,2,2$ & -3498.00 \\
& 2 & 2 & 0,1 & -3498.61 \\
& 3 & 2 & 2,2 & -3493.88 \\
& 4 & 1 & 2 & -3609.69
\end{tabular}

The order shows whether trajectories were fit with constant (0), linear (1), or quadratic (2). BIC bayesian information criterion

An insignificant effect of non-physically forced sexual activity on sport participation trajectories among men may be explained as follows. First, preliminary data suggest that women are more likely than men to be deleteriously affected by sexual assault [23-25].
Therefore, women victims of sexual assault may experience higher levels of psychological distress that can hamper their efforts to participate in sports. Second, extremely small samples of male victims (only 82 men experienced non-physically forced sexual activity) disguised the statistic results. Given the paucity of research on sexual assault in men, more research is needed on how sex differences interact with experiencing sexual assault to influence sport participation.

One interesting finding is that only non-physically forced sexual activity had significant effect on sport participation trajectory among women. According to attribution theory, perceived freedom to act is positively related to perceived internality [36]. If assailant and victim have engaged in voluntary social contact and if sexual assault does not involve physical force, blame and responsibility may be attributed to the victim and, therefore, some type of internal attribution about the victim can be made [37]. These suggest that victims whose assailants had used little or no

Table 3 The effect of physically (a) or non-physically (b) forced sexual activity on sport participation trajectories among male participants $(N=3147)$

\begin{tabular}{|c|c|c|c|c|c|}
\hline \multirow[t]{2}{*}{ Group } & \multirow[t]{2}{*}{ Parameter } & \multicolumn{2}{|l|}{ Model 1} & \multicolumn{2}{|l|}{ Model 2} \\
\hline & & Estimate & $(S E)$ & Estimate & $(S E)$ \\
\hline \multicolumn{6}{|c|}{ (a) Physically forced sexual activity } \\
\hline \multirow[t]{3}{*}{1} & Intercept & -3.082 & $(0.196)^{* * *}$ & -3.026 & $(0.276)^{* * *}$ \\
\hline & Ever forced to have sex in a physical way & 0.112 & $(1.012)$ & 0.128 & $(1.169)$ \\
\hline & Depression & & & -0.023 & $(0.049)$ \\
\hline \multirow[t]{4}{*}{2} & Intercept & 0.463 & $(0.120)^{* * *}$ & 0.768 & $(0.160)^{* * *}$ \\
\hline & Linear & -0.475 & $(0.069)^{* * *}$ & -0.504 & $(0.072)^{* * *}$ \\
\hline & Ever forced to have sex in a physical way & 0.494 & $(0.586)$ & 0.689 & $(0.591)$ \\
\hline & Depression & & & -0.082 & $(0.026)^{* *}$ \\
\hline \multirow[t]{4}{*}{3} & Intercept & 0.473 & $(0.167)^{* *}$ & 0.630 & $(0.188)^{* * *}$ \\
\hline & Linear & -0.074 & $(0.033)^{*}$ & -0.075 & $(0.029)^{*}$ \\
\hline & Ever forced to have sex in a physical way & -0.148 & $(0.624)$ & 0.014 & $(0.606)$ \\
\hline & Depression & & & -0.055 & $(0.024)^{*}$ \\
\hline \multicolumn{6}{|c|}{ (b) Non-physically forced sexual activity } \\
\hline \multirow[t]{3}{*}{1} & Intercept & -3.083 & $(0.196)^{* * *}$ & -3.021 & $(0.273)^{* * *}$ \\
\hline & Ever forced to have sex in a physical way & 0.496 & $(0.663)$ & 0.608 & $(0.694)$ \\
\hline & Depression & & & -0.020 & $(0.047)$ \\
\hline \multirow[t]{4}{*}{2} & Intercept & 0.446 & $(0.120)^{* * *}$ & 0.760 & $(0.160)^{* * *}$ \\
\hline & Linear & -0.473 & $(0.068)^{* * *}$ & -0.505 & $(0.071)^{* * *}$ \\
\hline & Ever forced to have sex in a non-physical way & 0.594 & $(0.488)$ & 0.824 & $(0.501)$ \\
\hline & Depression & & & -0.085 & $(0.026)^{* * *}$ \\
\hline \multirow[t]{4}{*}{3} & Intercept & 0.491 & $(0.166)^{* *}$ & 0.652 & $(0.187)^{* * *}$ \\
\hline & Linear & -0.073 & $(0.032)^{*}$ & -0.076 & $(0.028)^{* *}$ \\
\hline & Ever forced to have sex in a non-physical way & -1.003 & $(0.677)$ & -0.916 & $(0.682)$ \\
\hline & Depression & & & -0.053 & $(0.024)^{*}$ \\
\hline
\end{tabular}

${ }^{*} p<.05,{ }^{* *} p<.01,{ }^{* * *} p<.001$ 
Table 4 The effect of physically (a) or non-physically (b) forced sexual activity on sport participation trajectories among female participants $(\mathrm{N}=3356)$

\begin{tabular}{|c|c|c|c|c|c|}
\hline \multirow[t]{2}{*}{ Group } & \multirow[t]{2}{*}{ Parameter } & \multicolumn{2}{|l|}{ Model 1} & \multicolumn{2}{|l|}{ Model 2} \\
\hline & & Estimate & $(S E)$ & Estimate & $(S E)$ \\
\hline \multicolumn{6}{|c|}{ (a) Physically forced sexual activity } \\
\hline \multirow[t]{3}{*}{1} & Intercept & -3.721 & $(0.197)^{* * *}$ & -3.809 & $(0.321)^{* * *}$ \\
\hline & Ever forced to have sex in a physical way & -0.401 & $(0.560)$ & -0.300 & $(0.550)$ \\
\hline & Depression & & & 0.016 & $(0.042)$ \\
\hline \multirow[t]{4}{*}{2} & Intercept & -0.154 & $(0.122)$ & 0.042 & $(0.144)$ \\
\hline & Linear & -0.217 & $(0.017)^{* * *}$ & -0.219 & $(0.017)^{* * *}$ \\
\hline & Ever forced to have sex in a physical way & -0.239 & $(0.216)$ & -0.151 & $(0.225)$ \\
\hline & Depression & & & -0.047 & $(0.017)^{* *}$ \\
\hline \multicolumn{6}{|c|}{ (b) Non-physically forced sexual activity } \\
\hline \multirow[t]{3}{*}{1} & Intercept & -3.733 & $(0.208)^{* * *}$ & -3.877 & $(0.341)^{* * *}$ \\
\hline & Ever forced to have sex in a non-physical way & -0.049 & $(0.393)$ & 0.001 & $(0.407)$ \\
\hline & Depression & & & 0.026 & $(0.041)$ \\
\hline \multirow[t]{4}{*}{2} & Intercept & 0.131 & $(0.124)$ & 0.056 & $(0.145)$ \\
\hline & Linear & -0.216 & $(0.017)^{* * *}$ & -0.217 & $(0.018)^{* * *}$ \\
\hline & Ever forced to have sex in a non-physical way & -0.469 & $(0.207)^{*}$ & -0.412 & $(0.217)$ \\
\hline & Depression & & & -0.047 & $(0.017)^{* *}$ \\
\hline
\end{tabular}

${ }^{*} p<.05,{ }^{* *} p<.01,{ }^{* * *} p<.001$

force may experience more severe adjustment problems because they are especially prone to self-blame [37, 38]. Moreover, in a dating relationship of young people, non-physically forced sexual assault is actually shown to be perceived as socially permissible $[39,40]$. In our study, it is possible that severe adjustment problems caused by societal stereotypes that exacerbate victim blaming may have impaired victims' efforts to engage in sport participation among women who experienced non-physically forced sexual activity.

The effect of non-physically forced sexual activity on women's sport participation was considerably weakened and became insignificant after including psychological depression in the model as a potential mediator. This result partially supports our hypothesis which asserts that sexual assault victims engage in health risk behaviors because psychological distress caused by experiencing sexual assault hampers their efforts to promote their health. This result is also in line with previous studies showing that psychological distress mediated the effect of experiencing sexual assault on various health-related behaviors among women $[16,20,26]$. Further studies are needed to examine other potential mediators in addition to psychological depression when examining the effect of non-physically forced sexual activity on sport participation in women.
This study has several important limitations. First, since more specific information about sport participation was not available in Add Health data, individual sport participation could, therefore, not be distinguished from team sport participation. Moreover, only the number of days of participating in sports was considered in assessing sport participation. To understand more specifically the influence of experiencing sexual assault on sport participation, future studies need to use more precise measure of sport participation. Second, the small number of waves may have affected group membership and shape of trajectory. Only linear trajectory shapes appeared to be statistically significant, maybe because Add Health data had only four waves. Third, all the variables used in this study were measured by self-report questionnaires, which could introduce response bias or recall bias. Lastly, since this study analyzed a secondary dataset (Add Health data), it was impossible to consider other factors that may have contributed to the relationship between sexual assault and sport participation.

\section{Conclusion}

Despite these limitations, the findings of this study can be contributable to the literature by providing critical information on the effect of experiencing nonphysically forced sexual activity on women's sport 


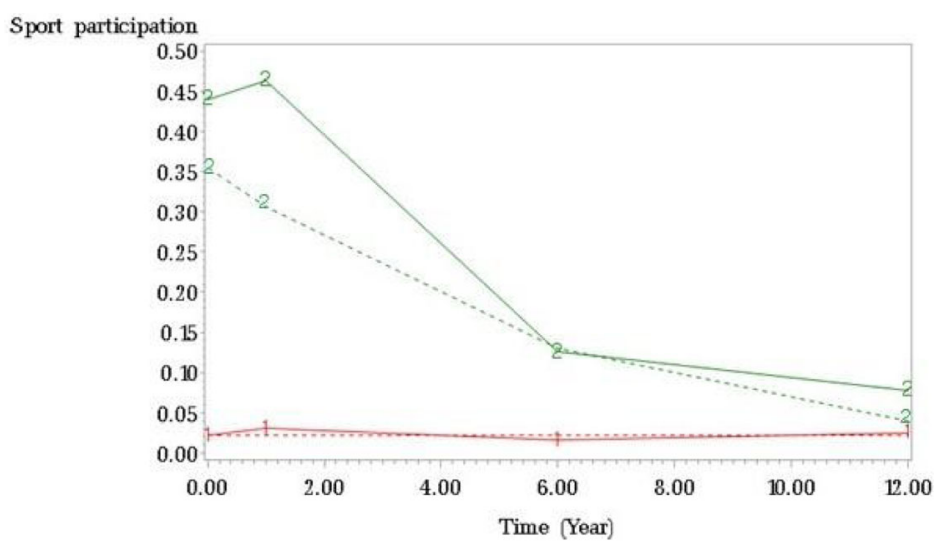

$+1+$ Low-stable group

222 High-decreasing group

$4-++4$ Female participants in low-stable group who have been forced to have sexual activity in a non-physical way before wave 1

z-2-2 Female participants in high-decreasing group who have been forced to have sexual activity in a non-physical way before wave 1

Fig. 2 Effect of non-physically forced sexual activity (ever) on trajectories of sport participation from adolescence through young adulthood among female participants. 22,2 Low-stable group. 22,2 High-decreasing group. $\$-\$-+$ Female participants in low-stable group who have been forced to have sexual activity in a non-physical way before wave 1. ₹-₹-? Female participants in high-decreasing group who have been forced to have sexual activity in a non-physical way before wave 1

participation trajectories from adolescence through young adulthood. Special care is required in developing sport promotion program for women victims of non-physically forced sexual activity. The results of this study also suggest that group-based trajectory modeling is a useful technique to examine distinct trajectories of sport participation from adolescence through young adulthood.

\section{Abbreviations}

ACSM: American College of Sports Medicine; Add health: National Longitudinal Study of Adolescent Health; CES-D: Center for Epidemiologic Studies-Depression Scale; BIC: Bayesian Information Criterion; SAS: Statistical Analysis System; ANOVA: Analysis of Variance

\section{Acknowledgements}

Not applicable.

\section{Authors' contributions}

CGL conceived of the study, drafted the manuscript, and performed the statistical analysis; JK helped draft the manuscript and perform the statistical analysis; HS and IO helped draft the manuscript; OK, JK, and JWP helped perform the statistical analysis. All authors read and approved the final version of the manuscript.

\section{Funding}

Not applicable.

Availability of data and materials

The datasets generated and/or analyzed during the current study are available in the [Add Health The National Longitudinal Study of Adolescent to Adult Health] repository, [https://www.cpc.unc.edu/projects/addhealth].

Ethics approval and consent to participate Not applicable.

Consent for publication

Not applicable.

\section{Competing interests}

The authors declare that they have no competing interests.

\section{Author details}

'Department of Physical Education, College of Education, Seoul National University, 1 Gwanak-ro, Gwanak-gu, Seoul 08826, South Korea. ${ }^{2}$ Department of Taekwondo, College of Sports Science, Woosuk University, 443 Samnye-ro, Samnye-eup, Wanju-gun, Jeollabuk-do 55338, South Korea. 
Received: 7 April 2020 Accepted: 28 May 2020

Published online: 10 June 2020

\section{References}

1. U.S. Department of Health and Human Services. Dietary Guidelines for Americans, http://www.health.gov/dietaryguidelines/2015/guidelines/. Accessed Sept 052017.

2. Centers for Disease Control and Prevention. Behavioral Risk Factor Surveillance System Survey Data. Atlanta: U.S. Department of Health and Human Services; 2009

3. Pepe MV, Gandee RF. Ohio senior Olympics: creating the new adult image In: Harris W, Harris R, Harris W, editors. Physical activity, aging and sports practice, program and policy. New York: The Center for the Study of Aging: 1992. p. 75-82.

4. Franklin B, Mitchell $\mathrm{H}$, Howley ET, et al. American College of Sports Medicine guidelines for exercise testing and prescription. 6th ed. Philadelphia: Lippincott Williams \& Wilkins; 2000.

5. MeSH Database. The National Library of medicine. The National Institutes of Health Available at: http://www.ncbi.nlm.nih.gov/mesh Accessed 17 Dec 172017.

6. Engberg E, Alen M, Kukkonen-Harjula K, et al. Life events and change in leisure time physical activity: a systematic review. Sports Med. 2012 42:433-47.

7. Breiding MJ, Smith SG, Basile KC, et al. Prevalence and characteristics of sexual violence, stalking, and intimate partner violence victimizationnational intimate partner and sexual violence survey, United States, 2011. MMWR Surveill Summ. 2014;63:1-18.

8. Campbell R, Dworkin E, Cabral G. An ecological model of the impact of sexual assault on women's mental health. Trauma Violence Abuse. 2009;10: 225-46.

9. Golding JM, Cooper ML, George LK. Sexual assault history and health perceptions: seven general population studies. Health Psychol. 1997;16: 417-25

10. Koss MP, Figueredo AJ, Prince RJ. Cognitive mediation of rape's mental, physical, and social health impact: tests of four models in cross-sectional data. J Consult Clin Psychol. 2002;70:926-41.

11. Littleton HL, Grills-Taquechel AE, Buck KS, et al. Health risk behavior and sexual assault among ethnically diverse women. Psychol Women Q. 2013; 37:7-21.

12. Ullman SE, Filipas HH, Townsend SM, et al. Trauma exposure, posttraumatic stress disorder and problem drinking in sexual assault survivors. J Stud Alcohol. 2005:66:610-9.

13. García-Moreno C, Pallitto C, Devries K, Stöckl H, Watts C, Abrahams N. Global and regional estimates of violence against women: prevalence and health effects of intimate partner violence and non-partner sexual violence. Geneva: World Health Organization; 2013.

14. Mackey T, Sereika SM, Weissfeld LA, et al. Factors associated with longterm depressive symptoms of sexual assault victims. Arch Psychiatr Nurs. 1992;6:10-25.

15. Ullman SE, Filipas HH. Predictors of PTSD symptom severity and social reactions in sexual assault victims. J Trauma Stress. 2001;14:369-89.

16. Orcutt HK, Cooper ML, Garcia M. Use of sexual intercourse to reduce negative affect as a prospective mediator of sexual revictimization. J Trauma Stress. 2005;18:729-39.

17. McCauley J, Ruggiero KJ, Resnick HS, et al. Forcible, drug-facilitated, and incapacitated rape in relation to substance use problems: results from a national sample of college women. Addict Behav. 2009;34:458-62.

18. Najdowski CJ, Ullman SE. Prospective effects of sexual victimization on PTSD and problem drinking. Addict Behav. 2009:34:965-8.

19. Nguyen HV, Kaysen D, Dillworth TM, et al. Incapacitated rape and alcohol use in white and Asian American college women. Violence Against Women. 2010;16:919-33

20. Ullman SE, Najdowski CJ, Filipas HH. Child sexual abuse, post-traumatic stress disorder, and substance use: predictors of revictimization in adult sexual assault survivors. J Child Sex Abus. 2009;18:367-85.

21. George WH, Martínez LJ. Victim blaming in rape: effects of victim and perpetrator race, type of rape, and participant racism. Psychol Women Q. 2002;26:110-9.

22. Harris K, Halpern C, Whitsel E, et al. The National Longitudinal Study of adolescent to adult health: research design, 2009. Available at: http://www. cpc.unc.edu/projects/addhealth/design. Accessed 10 Nov 2017.
23. Johnson $H$, Bunge VP, Johnson $H$. Prevalence and consequences of spousal assault in Canada. Can J Criminol. 2001:43:27-45.

24. Kimerling R, Rellini A, Kelly $V$, et al. Gender differences in victim and crime characteristics of sexual assaults. J Interpers Violence. 2002;17:526-32.

25. Tjaden $\mathrm{P}$, Thoennes N. Prevalence, incidence, and consequences of violence against women: findings from the national violence against women survey. Research in brief. Washington, DC: Department of Justice. Atlanta: National Institute of Justice, Centers for Disease Control and Prevention; 1998.

26. Goldstein AL, Flett GL, Wekerle C. Child maltreatment, alcohol use and drinking consequences among male and female college students: an examination of drinking motives as mediators. Addict Behav. 2010;35:636-9.

27. Meriwether RA, Lee JA, Lafleur AS, Wiseman P. Physical activity counseling. Am Fam Physician. 2008;77:1129-36.

28. Primack BA, Swanier B, Georgiopoulos AM, et al. Association between media use in adolescence and depression in young adulthood: a longitudinal study. Arch Gen Psychiatry. 2009;66:181-8.

29. Radloff LS. A self-report depression scale for research in the general population. Appl Psychol Meas. 1977;1:385-401.

30. Jones BL, Nagin DS, Roeder K. A SAS procedure based on mixture models for estimating developmental trajectories. Sociol Methods Res. 2001;29:374-93

31. Henson JM, Reise SP, Kim KH. Detecting mixtures from structural model differences using latent variable mixture modeling: a comparison of relative model fit statistics. Struct Equ Modeling. 2007:14:202-26.

32. Nagin DS, Odgers CL. Group-based trajectory modeling in clinical research. Annu Rev Clin Psychol. 2010;6:109-38.

33. Jones BL, Nagin DS. Advances in group-based trajectory modeling and an SAS procedure for estimating them. Sociol Methods Res. 2007:35:542-71.

34. Nelson MC, Gordon-Larsen P, Adair LS, et al. Adolescent physical activity and sedentary behavior: patterning and long-term maintenance. Am J Prev Med. 2005:28:259-66.

35. Telama R, Yang $X$, Viikari J, et al. Physical activity from childhood to adulthood: a 21-year tracking study. Am J Prev Med. 2005:28:267-73.

36. Kelley HH. Attribution theory in social psychology. Neb Symp Motiv. 1967; 15:192-238.

37. Mynatt CR, Allgeier ER. Risk factors, self-attributions, and adjustment problems among victims of sexual coercion. J Appl Soc Psychol. 1990;20: 130-53.

38. McCahill TW, Meyer LC, Fischman AM. The aftermath of rape. Lexington: Lexington Books; 1979.

39. Anderson ML, Kobek Pezzarossi CM. Is it abuse? Deaf female undergraduates' labeling of partner violence. J Deaf Stud Deaf Educ. 2012; 17:273-86.

40. Oswald DL, Russell BL. Perceptions of sexual coercion in heterosexual dating relationships: the role of aggressor gender and tactics. J Sex Res. 2006;43: $87-95$.

\section{Publisher's Note}

Springer Nature remains neutral with regard to jurisdictional claims in published maps and institutional affiliations.

Ready to submit your research? Choose BMC and benefit from:

- fast, convenient online submission

- thorough peer review by experienced researchers in your field

- rapid publication on acceptance

- support for research data, including large and complex data types

- gold Open Access which fosters wider collaboration and increased citations

- maximum visibility for your research: over $100 \mathrm{M}$ website views per year

At BMC, research is always in progress.

Learn more biomedcentral.com/submissions 